\title{
GLOBAL COMMODITY CHAINS \& WORLD INCOME INEQUALITIES: THE MISSING LINK OF INEQUALITY \& THE “UPGRADING” PARADOX
}

\author{
Benjamin D. Brewer \\ Department of Sociology and Anthropology \\ James Madison University \\ brewerbd@jmu.edu
}

\begin{abstract}
This article links key findings from two major research literatures within contemporary development and globalization studies: global commodity/value chains, and world income inequalities. Forging this missing link exposes what I call the "upgrading paradox" within commodity and value chain analysis. The paradox hinges on the disconnect between the global commodity/value chain literature's focus on the potential for firms and nations to "upgrade" their position within chains and the roots of the global commodity chain construct in worldsystems analysis, a theoretical framework that rejects the potential for widespread and generalizable developmental progress. Findings from the world income inequalities literature do indeed confirm the paradoxical nature of the upgrading discourse, so I conclude by discussing two potential paths for a "post-paradox" commodity chain analysis.
\end{abstract}

\section{INTRODUCTION}

The primary aim of this article is to forge an important, yet basically overlooked, link between two of the most prominent active research literatures within globalization studies - those of "global commodity/value chains" (or GCCs) and "global income inequalities." They have much in common, as both literatures have experienced an enviable efflorescence since the mid 1990s. Indeed, the global commodity/value chain perspective might now be considered one of the leading paradigmatic frames for defining and analyzing the causes and consequences of the global division of labor. Meanwhile, the measurement and evaluation of cross-national and/or global inequalities - within which income features centrally amongst different forms of social inequality - has enjoyed a renaissance over this same time with articles appearing in some of sociology's most prestigious generalist journals. This concurrent expansion in both fields is certainly not coincidental, for both bodies of work have taken up - albeit from different angles of vision and toward different ends - the same fundamental question: how have the (purportedly) massive changes in the structure and operation of the world economy associated with so-called globalization impacted the global (mal)distribution of wealth (a key dimension of what has

\footnotetext{
1 There is something of a divide in the literature between the "commodity chain" and "value chain" monikers. For our purposes here this distinction is essentially moot, although I will primarily use the GCC terminology, or both in tandem.
} 
usually been called "development") across the world's peoples and nations during the last forty years?

Yet, their shared timing and empirical agenda notwithstanding, findings from these literatures are rarely, if ever, explicitly connected by analysts working in either domain. This "missing link" is both puzzling and problematic for a number of reasons, not the least of which is that forging the missing link casts into relief what I call the "upgrading paradox" within global commodity chain analysis. As we shall see, the concept of "upgrading" - the idea that astute and rigorous analysis of commodity chains can illuminate opportunities for upgrading the competitive position of particular chain participants and lead to positive developmental outcomes - motivates much of commodity/value chain analysis. This faith in "development" - even if partial and contingent - is not particularly surprising; after all, a broader discourse of "production networks" circulates widely within the domain of contemporary development studies. What is paradoxical, however, is that commodity chain analysis is itself the intellectual offspring of a larger theoretical perspective - world-systems analysis - that has long hypothesized a persistent, unequal global distribution of wealth as a structural "fact" of a capitalist world-economy. Ironically, commodity chain analysis, with its emphasis on "upgrading," was first constructed as a means of illustrating precisely why general developmental progress is, at best, highly unlikely within the institutional structures of the capitalist world-system.

This theoretical paradox or disconnect within GCC/GVC analysis is made particularly apparent once the "missing link" to the world income inequalities literature is forged for, as we shall also see, evidence from the latter undermines the foundational assumption (often implicit) within the former that upgrading can lead to generalized national developmental progress. Indeed, some recent, and not-so-recent, findings from the most relevant measures of world income inequality support the basic world-systems hypothesis that the structure of income distribution across the capitalist world-economy remains quite stable over time - even if the positions of individual nations within that hierarchy (can) shift over time as a result of either upgrading or downgrading.

As such, the "upgrading paradox" poses a profound question for the commodity/value chains literature, namely: what value is the foundational concept of "upgrading" if the assumption that fostering more of it can create development turns out to be negated empirically? I argue that acknowledging the upgrading paradox in the light of the world income inequality literature does indeed seriously undermine the validity, and therefore the utility, of the "upgrading" frame. This negation, however, does not warrant an outright rejection of the commodity chain framework, for a theoretically reconfigured GCC analysis may well be one of the most useful and productive analytical optics through which ongoing changes in the global division of labor can be observed. Indeed, I argue that continued research from the commodity chains perspective is certainly worth undertaking, but that much greater attention must be paid to the links between industry-level changes, national-level upgrading and the broader world-historical contexts of power and inequality within which such changes are made. Commodity chain analysts must, in other words, no longer assume that upgrading within individual chains on the part of various firms and, by turn, nations will "add up" to significant shifts in global income inequalities. Shorn of the explanatory burden imposed by the upgrading frame, I believe future GCC/GVC analysis might proceed along either or both of two basic paths, one focused on more formalized/formalistic theory building, the other involving a more conscious return to the GCC framework's origins from world-systems analysis. Ultimately commodity/value chain analysis offers much insight into 
the dynamics of a global economy; I aim not to invalidate this approach but rather to critically clarify its theoretical underpinnings toward the goal of refining and improving these insights.

\section{PART I - THE GLOBAL COMMODITY/VALUE CHAINS PROJECT}

Since the mid-1990s the "global commodity chains" research perspective has gained significant influence amongst scholars of the global system and the political economy of development. The attraction has been primarily methodological, for GCC analysis offers tools for describing the structure and operation of the world economy in ways that move beyond the long dominant country-specific orthodoxy in development studies. The GCC approach does so by substituting the "commodity chain" for the nation-state as the unit of analysis within studies of development. The commodity chain denotes all of the various activities, processes and actors that are linked together to produce any given good or service, from initial inputs of raw materials, through manufacturing, transportation and distribution, and on to marketing, retailing, consumption and final disposal. ${ }^{2}$ So, rather than take the spatial boundaries of nation-states as a given starting point for analysis, the GCC perspective first identifies the functional steps within a given line of economic activity and then describes the particular geographical diffusion and organization of those activities as they cut across state boundaries.

As originally articulated in a 1994 volume edited by Gary Gereffi and Miguel Korzeniewicz, the analysis of a given commodity chain essentially proceeds across three dimensions: the technical and geographical dimension (the technical division of labor within a given chain, and the physical, social and political geography of that division of labor); the dimension of governance and power (how power is distributed across the social and technical division of labor within the chain); and the historical and institutional dimension (how the particular commodity chain "fits" into the broader world-economic context and interacts with broader world-historical dynamics). ${ }^{3}$ Cutting across these dimensions - or, really, pulling them together - is a general focus on the concept of so-called commodity chain "upgrading." In stylized form, the assumption within the literature has been that detailed empirical investigation and careful analysis of the geographical dispersion, governance structure and institutional context of a given commodity chain can help illuminate the ways in which the most powerful actors and agencies within the chain have been able to "drive" the organization of that chain to, above all else, their own benefit. As such, it has been assumed, or at least hoped, that GCC/GVC analysis could help to identify opportunities for commodity chain participants to "upgrade" the quality and/or intensity of their engagement with the chain in ways that should lead to developmental progress; this has been the primary policy appeal as well. Simply put, the GCC/GVC framework has generally seen "upgrading" as a primary goal and/or outcome of effective governance within a commodity chain as it is embedded within a particular historical/institutional context.

\footnotetext{
${ }^{2}$ Given its relative maturity, I will assume at least a minimal degree of familiarity with the GCC framework. For more detailed summaries, see: Bair 2005; Gereffi et al. 1994; Gibbon, Bair and Ponte 2008; Gibbon and Ponte 2005.

${ }^{3}$ In fact, the "institutional" dimension was elaborated a bit later (Gereffi 1995).
} 


\section{JOURNAL OF WORLD-SYSTEMS RESEARCH}

\section{The Uneasy Position of "Upgrading” in the GCC/GVC Project}

Although arriving from different theoretical angles and empirical foci, a recent spate of review pieces on the utility and future direction of GCC/GVC analysis (for example: Bair 2005, 2008; Dussel Peters 2008; Gibbon and Ponte 2005; and special issues of Competition \& Change and Economy \& Society) elaborate a coherent set of critical concerns emerging from within the perspective. These tensions come most directly to the fore through the discussion of so-called commodity/value chain "upgrading." According to Bair, "at the most basic level, the value chain literature defines upgrading as improving a firm's position within the chain, and this is generally associated with increased competitiveness that allows for the capture of greater value-added through the production process."(2005: 165) Translating this conceptual understanding of upgrading down to detailed empirical analysis presents a number of difficulties.

For one, there is the deceptively tricky question of operationalizing upgrading in practice, given the necessary constraints of any kind of "real-time" investigation into specific commodity chains as they evolve over time and across space. ${ }^{4}$ This is an issue of distinguishing between the means of upgrading with the ultimate end of upgrading. To paraphrase Bair, there are potentially many means by which a firm might "improve its position within [a] chain," but the primary end or goal of any such means is the "capture of greater value-added." As I discuss below, one of the theoretical strengths of the GCC construct in world-systems analysis has been its sensitivity to the notion that the particular activities comprising the global division of labor might shift both in their content and geographical dispersion even while the distribution of rewards for those activities might remain relatively stable. The challenge this presents for analysts focused on a single chain over a necessarily limited amount of time is in charting the "upgrading" efforts while simultaneously tracking the efficacy of such efforts in capturing greater value-added - that is in avoiding the potential for reification of activities or organizational forms as inherently "upgrading" or wealth-producing in their own right.

Secondly, even with upgrading clearly operationalized at the level of specific commodity chains and firms there remains the question: who, and in what proportion, benefits from the upgrading process? Many critics (Bair 2005; Bernstein \& Campling 2006 a,b; Collins 2005; Dussel Peters 2008; Palpacuer 2008) have noted the relative dearth of attention paid to questions of wealth distribution within commodity chain nodes or firms as they are grounded in specific places, with working conditions and labor relations ${ }^{5}$, or how such issues dovetail with racialized and gendered forms of social inequality and exclusion. In this regard - and in light of a few decades of work in the massive literature(s) on gender and development and, more recently, the ecological dimensions of economic development - it is not difficult to imagine how firm-level GCC upgrading might be completely divorced from meaningful gains in benefits captured by the majority of workers or other GCC participants at the comparatively local scale or at the point of production.

Finally, there remains the seemingly intractable problem of moving from individual chain analysis to the bigger picture of development at larger scales of analysis. As posed by Bair, "how

\footnotetext{
${ }^{4}$ I am grateful to an anonymous reviewer for pushing me to more clearly articulate this section on the means and ends of upgrading.

5 An exception to this is the adoption of GCC analysis by activist organizations and agents (see, for instance, Quan 2008 and the contributions by Raworth and Kidder, and Guthman in Bair 2009).
} 
does one translate the process of upgrading at the level of the firm into its implications for the larger units that are traditionally regarded as the spaces or containers of development, such as the national or regional economy? Put differently, how do we aggregate up and out from the firm level?"'(2005: 166) This is really a question of both intra and inter chain dynamics, as well as the broader temporal frame for analysis. Within a given commodity chain we face the aforementioned issue of connecting meaningful improvements in the capture of value-added to upgrading strategies pursued by agencies in the chain. And, developmental progress at larger scales hinges not just on successful upgrading at the level of the firm, but indeed successful upgrading across firms and commodity chains within a given territory. In both cases, the temporal dimension is equally important - after all, comparatively short-term gains in valueadded generated by seemingly successful upgrading strategies might, in the longer run, diminish in the face of growing competition brought on by the earlier success of the strategy itself. Obviously all temporal frames are ultimately limited (and the relevant frame is not somehow, $a$ priori, immediately clear); this is only to highlight the difficulties of aggregating not just across space but also over time. Nevertheless, absent the means of analyzing this more generalized upgrading at the level of the "forest," GCC analysis may well leave us overwhelmed by the "trees" of individual chains or nodes within them.

\section{A Theoretical Re-Grounding of the GCC Project}

As we can see, upgrading causes trouble for GVC/GCC analysis - even while, at the same time, serving as a core organizing concern for the framework. However, placed in the broader intellectual context from which commodity chain analysis emerged, the trouble is perhaps more understandable. Indeed, this trouble with upgrading derives from a contradiction - which I call the "upgrading paradox" - introduced by the shift from the more explicitly world-systems variant of commodity chain analysis to the GCC focus of the 1990s. Indeed, the expansion of the upgrading discourse within GCC/GVC analysis is arguably the primary and most significant way in which this literature broke with its world-systems roots, for this latter mode of analysis has been profoundly pessimistic in its evaluation of the chances for the majority of the world's population to "develop" and attain core standards of wealth. The paradox, then, is that we have a contemporary research program that is focused on unlocking the keys to successful commodity chain upgrading, but which is itself an offshoot of a theoretical framework that views "national development" as an "illusion."(Wallerstein 1991) More precisely, much of the GCC/GVC upgrading discourse presumes, whether explicitly or implicitly, that significant income increases (and the particular upgrading strategies presumably leading to them) can not only be achieved by some developing countries or regions, but can be achieved, in theory, by most or all of these places through a generalized set of upgrading strategies. In the light of this theoretical divergence, reconsideration of the function of the commodity chain construct within the world-systems framework is in order.

Terence Hopkins and Immanuel Wallerstein (1977) introduced the "commodity chain" terminology as part of their efforts to articulate the methodology and theoretical dimensions of their program for "world-systems analysis." In speaking of commodity chains they sought to move beyond the strictures of orthodox development studies, most fundamentally by rejecting the standard focus on national development as a distinct process that could be explained in relative isolation from broader, supposedly exogenous, world-economic dynamics. In Wallerstein's 


\section{JOURNAL OF WORLD-SYSTEMS RESEARCH}

explication of social change, the world-system - which is to say a social system spatially integrated through a division of labor such that it functions as a world unto itself (Wallerstein 1974, 2004: 16-17) - is the fundamental unit of analysis, not the state-controlled jurisdictions by which the modern world-system has been parsed out politically. As such, the commodity chain terminology was of a piece with this larger advocacy for a shift in the unit of analysis for development studies, from the nation-state or specific "national" industries to the various commodity chains that, taken in total, comprised a world-economy.

Conceptually, the entire world division of labor consists of the sum total of all commodity chain nodes and linkages at a given time. If this is the structure of the world-economy looking synchronically, what of the diachronic dynamics within this division of labor that cause it to change over time and to create or reinforce inequalities in wealth? In Wallerstein's view the distinct and specific nature of capitalist competition within and across commodity chains leads to polarization - such that, "the total surplus extracted in these commodity chains was at no point in time distributed evenly in terms of the geographical location of the creation of the surplus."(Wallerstein 1991: 109) As elaborated by Arrighi and Drangel, "the nodes or economic activities of each and every commodity chain tend to become polarized into positions from which the pressure of competition has been transferred elsewhere (core-like activities) and positions to which such pressure has been transferred (peripheral activities)."(1986: 17) Thus, the degree of competition within the commodity chain nodes determines their levels of remuneration, not some inherent, essential quality of the activity itself, for "no particular activity....is inherently core-like or periphery-like. Any activity can become at a particular point in time core-like or peripherylike, but each has that characteristic for a limited period." 6 (Ibid.: 18)

How does this translate back down the level of nation-states, development and crossnational variations in income? Countries, for this purpose, can be seen as containers holding a huge array of different commodity chain nodes and activities - some of which are relatively profitable (Arrighi and Drangel's "core-like" activities) and some of which are not ("peripherylike"). All countries contain a variety of activities; wealthy countries still contain an assortment of low-yield activities while poor countries nevertheless contain some high-yield activities. The difference lies in the mix of such activities contained by a given country - within wealthy/core countries the relative proportion of high-yield activities is much higher than in poor/peripheral countries. For a number of reasons, these proportional balances are predicted to remain relatively stable over time. Although such reasons in their full complexity lie beyond the scope of the current article, they have mainly to do with state formation, political power, and the role of state power and violence as they overlay the global division of labor and the distribution and maintenance of higher-value GCC nodes (Arrighi \& Drangel 1986; Arrighi, Silver \& Brewer 2003; Wallerstein 2004, 2009)

Here we reach the distinguishing characteristic of the world-systemic understanding of global inequality. The particular mix of activities predominant within the core regions of the world-economy can, and most certainly does, change quite significantly across time (e.g. the major shifts in the "leading sectors" of the world economy over the past few centuries). Yet, while the mix of activities predominant in the core is expected to be dynamic and fluid, the overall distribution of wealth generated by those activities should remain essentially the same over time. Thus, the commodity chain concept within world-systems analysis was created, first and

\footnotetext{
${ }^{6}$ For a similar treatment, but phrased in the terminology of rents, see Kaplinsky (2005: 57-84).
} 
foremost, as a means of explaining the polarized distribution of wealth within the modern capitalist world-system. The central world-systems "hypothesis" in this regard is that a durable, three-tiered (or trimodal) distribution of world income will be a persistent structural reality within the modern world-system, even if there is mobility on the part of individual countries or groups of people within them. Reframed in the terms of commodity chain analysis, upgrading may be possible for some people, firms or countries, but so too is downgrading also possible; over the long run, these will tend to balance each other out such that a roughly similar world-systemic distribution of wealth is maintained over time. For this reason, Wallerstein can therefore assert that national development is illusory for it is not available to all even if it is, and obviously has been, available to some.

From this brief exegesis we can see how the upgrading discourse within GCC analysis introduces a potentially powerful contradiction into the theoretical framework guiding such work. The notion of generalizable upgrading runs directly counter to the world-systems claims about the structure of global income inequality. Of course, this is fundamentally an empirical question. If the structure of cross-national income over time resembles the distinctly trimodal distribution implied by world-systems analysis, this is evidence that "upgrading" is indeed paradoxical and in need of theoretical reconsideration. We therefore turn next to the global income inequalities research literature.

\section{PART II - GLOBAL INCOME INEQUALITIES \& THE UPGRADING PARADOX}

Parallel to the emergence of the global commodity chains literature across the 1990s has been a resurgence of interest in the measurement of how wealth is distributed across countries, regions, and individuals in the global system.(Babones 2002, 2005; Firebaugh 1999, 2000, 2003; Firebaugh \& Goesling 2004; Goesling \& Baker 2008; Korzeniewicz \& Moran 1997, 2000; Mann and Riley 2007; Milanovic 2005; Mills 2008; Sutcliffe 2004; Wade 2004 a,b) In this section I offer not a detailed analysis or critique of the global income inequalities literature in its entirety, but rather an abbreviated summary of salient debates within as they pertain to the upgrading paradox in GCC/GVC analysis. Without overstating the certainty of any results derived from existing data (all of which involve their own compromises and limitations), I will argue that the most relevant income inequality research does in fact support my notion of the upgrading paradox within GCC/GVC analysis.

The world income inequality literature is voluminous and contentious. While comprehensively reviewing this work may have driven Bob Sutcliffe to ultimately conclude that it "is futile to summarize anything as complicated as world inequality in a single figure,"(2004: 33) we might find a bit more encouragement from Robert Wade's response to the question, "what is the trend of world income distribution?" - that being, "it depends."(2004a: 166) The degree to which "it depends" hinges primarily on the particular theoretical concerns guiding data selection and data analytic techniques. More concretely, one's conclusions about world income inequality will be most strongly influenced by a few key decisions: whether and how to weight national income data by population, whether to compare income data across countries using foreign exchange or purchasing power parity adjustments, and whether one includes China and/or India in the analysis (and, by turn, the analyst's confidence in the validity of the income data from both countries).(Babones 2002; Mills 2009; Moran 2003; Sutcliffe 2004; Wade 2004 a,b) While the 
question of population weighting is driven almost solely by conceptual concerns, these last two questions hinge just as much on pragmatic data concerns as theoretical and conceptual issues.

Income data adjustments attempt to account for the differences in purchasing power produced in local markets by equal amounts of the currency used for cross-national comparison (e.g. a dollar's purchasing power is greater in Brazzaville than in Baltimore). Debates in the literature have mainly focused on the conceptual issue of whether income conversions based on foreign exchange (FX) ratios or purchasing power parity (PPP) estimates more effectively measure welfare and poverty as they are experienced on the ground. The prevailing consensus concludes that FX figures best capture comparative command over world resources while PPP figures more accurately capture welfare and comparative living standards.(Firebaugh and Goesling 2004: 291) However, often overlooked in such discussions are the serious data quality problems that plague the PPP project in particular.(Dowrick and Akmal 2005; Korzeniewicz et al. 2004; Wade 2004 a,b) What is more, the unreliability of PPP adjustments as well as the imprecision of data on intra-country income distribution, is most pronounced in the case of China - which, due to both its size and particular developmental trajectory, turns out to be the determining case for virtually all measures of global income inequality. Simply put, most every conclusion to be drawn about the distribution of world income hinges on the influence of the demographic giants of China and India, yet these are the cases with some of the most problematic data. $^{7}$

For what concerns our inquiry, the conclusion to be drawn from the debates in the world income inequality literature is, first and foremost, that data selection must be attuned to our theoretical questions and concerns. Secondly, we must recognize the large degree of uncertainty in all such measures. With respect to our theoretical concerns, GCC/GVC upgrading, as we have seen, is most often framed in terms of comparative performance in capturing a greater proportion of the total value-added along the chain, or what amounts to a zero-sum game in which upgrading for some comes, to some degree, at the expense of others. The operational definition of upgrading, and the presumed way in which upgrading might lead to developmental progress within the literature, assumes that firms and states are embedded within a competitive, global market space in which Northern standards of developmental success set the bar by which Southern participants must compete and judge their own success. And while the GCC/GVC construct is fundamentally grounded in firms, industries and chains, the broader notion of upgrading ultimately reconnects to country-level changes as the proper unit in which developmental gains can be observed. Given our focus on "catching-up" through upgrading within global commodity chains we are here most interested in comparative or relative measures of cross-national income inequality.

\footnotetext{
${ }^{7}$ Dowrick and Akmal, for instance, argue "that all international comparisons of average real income for China are based on estimates, not on direct price measurement," and that, "until the publication of the 2004 ICP [International Comparison Project] survey, which for the first time includes both India and China, all methods of calculating purchasing power parities have to resort to imprecise estimates of real income for more than one third of the world's population."'(2005: 219, 226) Likewise, Robert Wade argues the PPP adjustment for China is "based on guestimates [sic] from small, ad hoc price surveys in a few cities, adjusted by rules of thumb to take account of the huge price differences between urban and rural areas and between eastern and western regions...The price comparisons for India are extrapolations from 1985 qualified by later ad hoc price surveys."(2004a: 572)
} 
Turning to a review of the findings, I will first consider the strand of the world income inequality literature that is most explicitly attuned to the particular world-systems claims about the structure or shape of the world income distribution. Giovanni Arrighi, Beverly Silver and Benjamin Brewer have shown that, as a proportion of First World (or Northern) national incomes, Third World (or Southern) incomes remained virtually locked in place from 1960-1999 hovering at about 4.5\% of First World GNP per capita.(2003: 13) While Arrighi et al. demonstrate a distinct lack of "catching up" for the Third World/Global South as a whole lending credence to the world-systems claim that the stratification of the world-system remains quite stable over time - a few other studies have measured state and individual level mobility in finer detail. In fact, these all follow the trail initially opened up by Arrighi and Drangel in their 1986 paper in which they sought to measure the distribution of world population by income level (also addressed by Arrighi 1990). Arrighi and Drangel found that the Wallersteinian specification of the core, semi-periphery and periphery corresponded quite well to the data during much of the twentieth century - or, putting aside the world-systems terminology - that the global income distribution was distinctly trimodal. What is more, their analysis of country-level mobility showed some notable instances of upward and downward mobility, but that over the long-run of the study (rather than smaller periods within) mobility was certainly the exception rather than the rule.

Miguel Korzeniewicz and William Martin (1994) first updated and extended this analysis, adding newer data and more time points, and coming to essentially the same conclusion as Arrighi and Drangel. Then, after a pause of close to twenty years, a few articles have appeared more recently that take the original Arrighi and Drangel piece as their starting point, two of which are most germane to our argument. Salvatore Babones' (2005) update and replication of the Arrighi and Drangel analysis closely adheres to the conceptual underpinnings guiding that paper. Babones extends this work, however, by developing a far more refined and systematic method for distinguishing zonal/regional divides within the overall income distribution. His findings are unambiguous, and they directly reinforce Arrighi and Drangel's claims. Specifically, he notes "the existence of a tri-modal distribution of countries (weighted by population) in the distribution of national incomes is unmistakable," and that "the structure of the world-economy has been very stable over time, with little mobility across boundaries of its three zones."(Babones 2005: 47; 51)

Along these same lines, Raymond Dezzani has also directly examined Wallerstein's trimodal distribution claim. Methodologically, Dezzani's approach diverges from the Arrighi and Drangel lineage, relying instead on a form of analysis that measures the relative stability of the zonal groupings of countries over time. His conclusions are almost exactly the same both Babones and Arrighi and Drangel:

"Thus, although the developmental hypothesis that countries are upwardly mobile has merit, empirical results suggest that very little impact is observed in the worldsystem because countries moving upward in the world-economy region sequence are nearly balanced by countries moving down the sequence."(Dezzani 2002: 595)

Moving beyond the relatively small, world-systems derived "structure of world income inequality" strand of the literature, we can find further evidence in support of the upgrading paradox. Again the key is in focusing on the measures most germane to our inquiry and, yet again, we must account for the data limitations affecting all such measures. Especially within the 


\section{JOURNAL OF WORLD-SYSTEMS RESEARCH}

mainstream of the world income inequalities literature in sociology, one particular conceptualization and measure of inequality has predominated: population-weighted, PPP adjusted, so-called global income inequality. In this calculation, within-country income inequality measures are combined with between-country income inequality to estimate the total global individual level distribution of income. ${ }^{8}$ Conceptualized and measured this way, most every study has indicated either that global income inequality has been gradually diminishing since the 1970s or 1980s or that it has remained stable.(Firebaugh and Goesling 2004; Goesling and Baker 2008; Sutcliffe 2004: 25)

To be sure, this "standard" measure is useful in estimating the total distribution of income across humanity, and in trying to measure that income in terms of the welfare it provides. However, this does not mean it is the only, nor even the most important, measure of income inequality. For one, questions of the quality of the PPP data remain, and a dataset of truly comparable within-country inequality data is not easily constructed. ${ }^{9}$ In seeking evidence most appropriate to the upgrading paradox, global income inequality - even if perfectly measured - can also disguise cross-national differences in income distribution that are equally, if not more, relevant to the concept of upgrading and catching up. In fact, synthesizing from the literature, it seems that world income inequality has remained unchanged or has intensified when measured by virtually any other combination of data sources, operationalizations of inequality, and population weighting schemes, beyond population-weighted, PPP adjusted data. Remove China from the analysis, and the trend of lessening inequality essentially disappears, even using the same data and methods. To be sure, no comprehensive summary of trends in world income distribution that ignored China could, or should, be taken seriously; however, China's demographic weight is such that this country's trajectory largely determines our conclusions about world-scale trends.

In fact, for what concerns the upgrading paradox, the case could actually be made that unweighted measures of between-country inequality are most appropriate, for upgrading is not an individual level outcome - nor, in the bigger picture, even a single firm-level outcome. If, to be a meaningful concept in development studies, "upgrading" as a process must ultimately translate up and out to a broader regional or national context, we must compare the relative developmental performance of countries alongside the distribution of income by individuals worldwide. The trend in unweighted, between-country inequality seems as clear as things can be in this literature: "there is little or no evidence for persistent convergence between countries."(Sutcliffe 2004: 20; see also Goesling and Baker 2008: 185, for similar results) Although humankind in toto might have seen a lessening of global inequality through China's national-level average income improvements, the benefits of this development were and are, of course, not available to citizens of other countries - even putting aside the issue of whether the benefits accruing to (some of) China's citizens came at the expense of those living elsewhere. What is more, China's impact on global income inequality has been mainly to level the middle of that distribution; an impact that is

\footnotetext{
${ }^{8}$ More specifically, information on each country's internal distribution of income is combined with average national income data to estimate (by population quintile, for instance) the household or individual level distribution of incomes.

${ }^{9}$ For instance, reliable internal income distribution data on China are difficult find. Yet, given that a single quintile of China's population is almost equal to the total population of the entire United States, any definitive answer on global income inequality hinges on the quality of the within-country inequality estimates for China.
} 
most pronounced in integrated measures of distribution (e.g. the Gini coefficient) rather than measures of polarization or differences in the extremes of the distribution.

Looking at these relative or comparative measures of polarization and the ratios of incomes (which was the focus of the already-discussed Arrighi et al. 2003 article), what becomes apparent is a trend of increasing polarization the more extreme the proportions of the distribution one compares. Although the ratio of the average income of the top 50\% to the bottom $50 \%$ may have fallen since 1980, the same ratio for the top $1 \%$ to the bottom $1 \%$ has grown by close $100 \%$ over this same time (Sutcliffe 2004: 28, Table 5). As before, I am not arguing that any one such measure captures "real" inequality while the other ignores it, for all such measures provide insight into aspects of the phenomena at hand. Looking across all of these various measures, though, a story emerges in which large-scale income improvements in large countries (China and India, to a lesser extent) - moving from the low end toward the middle of the distribution - flatten the individual-level distribution of world income while cross-national and ratio-of-extremes forms of income inequality remain unchanged or even increase.

In sum, then, a series of recent contributions to the world income inequalities literature studies, it must be emphasized again, that have focused on the particular conceptualization of relative poverty and "catching up" implied by much of the GCC upgrading discourse - all reinforce the core claim about the stratification of the world-economy made by the world-systems perspective. While the strand of the world income inequality literature that is most tailored to the specifically world-systems predictions directly supports the upgrading paradox, a large body of evidence from the broader and more mainstream income inequality literature also reinforces this conclusion. ${ }^{10}$ It therefore appears that the kind of generalized, or, more precisely, generalizable, developmental possibilities implied by the GCC upgrading discourse are not borne out by the empirical evidence of the past forty years that we have available. As such, what I have called the "upgrading paradox" within GCC/GVC analysis does in fact challenge some of the core tenets of the GCC framework. In light of this verification of the paradox, in the final section of this essay we shall draw out the different implications this has for the future directions of GCC analysis.

\section{PART III - TOWARD A POST-PARADOX GCC ANALYSIS?}

What does it mean for GCC/GVC analysis to acknowledge the paradox at the heart of the framework's reliance on "upgrading" as a fundamental explanandum? There is no single answer to this question, for it depends on the theoretical purposes toward which the commodity chain framework is applied. Most certainly, though, the upgrading paradox does not somehow invalidate GCC/GVC analysis as a whole, for acknowledgement of the paradox demands only that analysts rethink, and ultimately make more explicit, the particular thrust of their work. In this respect, closer attention to the movement across analytical and spatial scales is needed. The

10 Space constraints preclude further discussion in this paper, but it is noteworthy that Sutcliffe's comprehensive review of the income inequalities field closes with the conjecture that the "shape" of world income distribution may be equally important as absolute incomes and their global distribution. He goes so far as to say a bi- or tri- modal distribution would imply a different political and economic reality than a uni-modal distribution (2004: 36), but seems to be unaware of the world-systems strand of the literature that is focused primarily on this very question! 
Wallersteinian critique of the developmentalist framework hinged on the disconnect between observable increases in national wealth (development) in some formerly less-developed locations and a broader structural reality in which, it was argued, such opportunities were not possible for all less-developed areas. As such, successful upgrading strategies identified by GCC/GVC analysis of specific chains as they are connected to specific places at specific times cannot, by definition, be broadly adopted by other actors (e.g. firms, states) to yield similar results. The paradox therefore resides in this disconnect between "sub-systemic" units of activity (and lessons drawn from the study of such units) and durable, "systemic" distribution patterns. In short, there is an "adding up" problem (Arrighi and Drangel 1986), or a "fallacy of composition" (Kaplinsky 2005).

Thus, upgrading, even as defined by the GCC/GVC literature and even in the light of the empirical evidence provided by the world income inequalities literature, is not ruled out theoretically at the level of individual firms - nor even at the level of nation-states or world regions. This is because none of these forms or levels of upgrading, taken in relative isolation, speak to the broader issue of systemic and global income inequality. Yet, it is precisely this issue that has long animated so much of the "development" discourse, whether phrased in the terms of "catching up" through modernization, the "convergence" of mainstream economics, or in today's concern with the "North-South Divide."

As a brief aside, it is worth noting the almost complete exclusion of non-income and non profit-oriented conceptualizations of "development" from the GCC/GVC literature. Indeed, conspicuous in their absence are most all such welfare-oriented conceptualizations of poverty, whether framed in terms of "basic needs," the Human Development Index, "physical quality of life" (Morris 1979), or a "capabilities" approach (Sen 1999). Given the immense scope and variety of such critiques of the developmentalist presumption that income and/or wealth serve as useful and robust proxies for well-being and welfare ${ }^{11}$, this additional "missing link" between GCC analysis and the poverty and well-being literature is certainly worthy of attention; it is also certainly beyond the purview of the present article. Suffice it to say, however, that GCC analysis need not remain silent on the issue, for the commodity chain construct is well suited to highlight the interface between the global division of labor and local conditions, social structures and inequalities. As such, it is not difficult to envision how commodity chain analysis could be used to demonstrate why and how firm-level growth has, and has not, improved welfare or well-being in different places, at different times, and by other measures. In other words, one future path for GCC analysis might explicitly focus on "upgrading" defined in terms other than income, or, by fixing the analysis in space, examine the connection between instances of income upgrading within particular GCC nodes and associated welfare upgrading as they may or may not have followed "on the ground."

\section{Two Paths for GCC/GVC Analysis}

Presuming that comparative income performance will remain a (if not the) guiding concern for GCC/GVC analysis, we still face the existential challenge to the perspective generated by the upgrading paradox - that is, why undertake GCC/GVC analysis if upgrading turns out to be a

\footnotetext{
${ }^{11}$ See Brady, Kaya and Beckfield (2007) for a recent empirical unpacking of what they call the "growth consensus" presumption that income naturally conveys well-being.
} 
"mirage" of sorts? I believe there are likely two distinct, but not mutually exclusive, paths: the first of these working toward a more formalistic program of theory building; the second toward a return to GCC analysis' world-systems roots through a renewed emphasis on the structure of social inequality within the world-system and the mechanisms by which such inequalities are reproduced within the global division of labor. Let us consider each in turn.

Formalistic theory building. The strongest example of the turn toward more formalistic theorybuilding agenda within the value chains stream is a programmatic piece by Gereffi, Humphrey and Sturgeon that appeared in 2005. In this article, Gereffi et al. make a first stab at specifying a more generic theory of value chain governance by focusing on various product, firm and transaction attributes and how they combine in different ways to yield different organizational and governance forms observed within value chains. What Gereffi et al. sketch out is a form of GVC analysis in which the organizational structure of value chains serves as the core dependent variable, variations within which can be predicted by a series of three dichotomous independent variables: the complexity of transactions, the ability for transactions to be codified, and the underlying capabilities or skill level of suppliers. Undoubtedly, Gereffi, et al.'s article is the most formalized attempt within the GCC/GVC literature to construct an industry-neutral theory of economic organization, and it represents an impressive first step in the "theory-building" direction for the value chain literature.

As Sturgeon clarifies in his own reconsideration, this piece was not intended to be "a grand theory of globalization or economic development." Rather, the 2005 article represented for its authors "a more modest theory of linkages, or, perhaps better, a theory that seeks to explain and predict how nodes of value-adding activity are linked in the spatial economy."(Sturgeon 2009:123) Sturgeon has in mind a "modular" and primarily inductive program of theory building for value chain analysis (Ibid.: 111, 133-135) in which particular causal mechanisms are isolated and explained in order to, eventually, be plugged back in to other such explanatory modules for a more general theory. There is no reason such a direction for value chain analysis cannot also coexist with the upgrading paradox. For one, its inter- and intra-firm focus is essentially agnostic about the broader context of global income inequalities. And, as a practical matter, this form of value-chain theory building could even inform firm or state-level policy interventions under the rubric of upgrading - although this could only be justified theoretically via the caveat that generalized "lessons" for upgrading could not be gleaned from such an exercise.

Alternatively, this form of value chain theory building might sidestep the upgrading paradox by adopting a more abstract perspective centered on the identification and explanation of different forms of economic organization as its outcome of interest, or explanandum. After all, this is precisely what is implied by treating "organizational form" as dependent variable, and as a mode of analysis there is no reason this would be more or less useful. Commodity chain analysis from this perspective would be considered a useful addition to the general analytical toolbox for an economic sociology of production network formation. Most important in all this would be a more clearly specified reason for pursuing chain analysis of whatever sort. The upgrading paradox cuts to the heart of one of the more popular such "hooks" guiding the current literature, but clearly there are ways around this, as just discussed. However, so long as upgrading returns as the ultimate justification/hook for value chain analysis, the paradox remains. And, while upgrading may not be explicitly at the center of this more formalistic branch of value chain theorizing (in the sense that a measure of upgrading itself is not taken as the dependent variable), 


\section{JOURNAL OF WORLD-SYSTEMS RESEARCH}

the broader upgrading frame nonetheless remains deeply embedded, implicitly, in this work. To wit, we need only refer to the opening lines of this same piece by Sturgeon, in which he states, "recent changes in the global economy...have rendered static notions of permanent dependency and underdevelopment obsolete. Regions, countries, and individual localities can improve their relative position in the global economy. The much-debated question is: How?'(Ibid.: 110, emphasis mine) While upgrading itself may not be the immediate outcome of interest to be explained by this form of theory building, the broader enterprise is still justified through the upgrading rubric.

World-historical reproduction of inequality. A second path would involve jettisoning the "upgrading" frame outright and focusing future commodity chain analysis instead on the identification and explication of particular mechanisms by which the broad patterns of durable income inequality have been reproduced across the space and time of the capitalist worldeconomy. In effect, this would make the reproduction and reorganization of global income inequality - and not necessarily its lessening - the "hook" for GCC analysis. Shorn of the analytical burden imposed by the upgrading discourse, GCC analysis would fall back on its original strength - namely, offering a structural and systematic, but also holistic, way to describe and analyze shifting patterns within the global division of labor. What is more, this approach need not preclude a systematic form of typology building and theory construction, even if this would differ from the more formalistic form of theory construction charted by the first path. Indeed, synthesis from the substantial (and steadily expanding) base of empirically-grounded GCC/GVC studies would likely already yield a set of more generic mechanisms by which reorganization in the global division of labor has reproduced, or transformed, the distribution of world income.

To be clear, this second path for GCC analysis would not simply focus on "proving" that "development" is an illusion - that is, some kind of Sisyphean task of demonstrating perpetual stasis in the modern world-system. To the contrary, I see this path directed toward elaborating, contextualizing and clarifying a foundational theoretical claim within world-systems analysis that is germane to all of development studies. This claim about both the possibility for, but systemic limitations to, upward mobility within the structure of income stratification of the capitalist world-system, challenges the orthodoxy of both (neo)classical or modernization perspectives as well as the conventional reading of the dependency framework. For this very reason, Wallerstein's argument about the structure of income inequality in the capitalist world-system remains under-recognized and under-analyzed - in spite of the renaissance in the cross-national and global inequalities research literatures. In returning to this theoretical pillar of world-systems analysis, GCC analysis would also address one of the major criticisms leveled at Wallerstein's perspective - that being its alleged tendency toward a functionalist, deterministic or teleological mode of explanation. In the case of global income inequality more specifically, the critique normally runs that Wallerstein makes a general system-level claim without ever specifying the causal pathways by which such systemic outcomes are actually created. ${ }^{12}$ Without further specification or explanation, the assertion of a trimodal income distribution risks a functionalist

\footnotetext{
${ }^{12}$ For a recent and cogent example of this critique, see Herman Schwartz's (2007, particularly pp. 119-121) intervention in an ongoing debate within Studies in Comparative International Development initiated by the publication of Arrighi et al.'s (2003) piece in the same journal.
} 
inflection in so far as this particular distribution allegedly fulfills some kind of systemic "need" even if there is no single, "systemic" agency to express or demand such a need. ${ }^{13}$

To date, the most extensive elaboration of a distinctively "commodity chains" theory of the reproduction of world income inequalities has been the 1986 article by Arrighi and Drangel cited above. This piece started from a forceful critique of much of Wallerstein's writings on commodity chains and world-systemic inequality, advancing GCC analysis beyond Hopkins' and Wallerstein's fairly stylized and loose notion of commodity chains. However, while Arrighi and Drangel articulated a more systematic theory of world-systemic stratification using the commodity chain terminology, the piece nonetheless had its limitations in guiding the more grounded empirical work that would subsequently be undertaken by the first generation of GCC analysts. In fact, the great strength of this piece, for its intended analytical purposes, turns into its weakness for chain-level research - this being the authors' intentional abstraction from the specific activities comprising the world division of labor and their reorganization over time.

As we have seen, Arrighi and Drangel argue that these activities are subjected to emulation and competition such that high-return activities over time tend to diminish toward lower returns. Rather than focus on these activities and the ways in which "core" regions succeed in (temporarily) monopolizing high-return activities or generating new such activities, Arrighi and Drangel assume that, over the long run, this dynamic will result in a stable polarized distribution of world income with few instances of mobility across the zones of the distribution. To the extent that their empirical analysis of world income inequality demonstrates this sort of long-run stability, their presumption, that dynamic shifts in the "mix" of activities occurring in the zones of the world-system have not added up to significant changes in the remuneration attached to those activities (in the aggregate), seems reasonable. Nonetheless, by effectively operationalizing the degree of competition within commodity chain nodes and activities as the measure of income distribution itself, Arrighi and Drangel unfortunately provide only circular explanation for those seeking insight into commodity chains as they are situated in specific places and times.

The tautology at the heart of Arrighi and Drangel is as such: "core" activities (a comparatively high proportion of which are grounded in core countries) yield high value-added returns because they are sheltered from competition...and we infer they are sheltered/core-like because core countries are engaged in them! Obviously this does not suffice as an explanation for how particular activities and chains are sheltered from/subjected to the forces of competition, nor does it even offer much insight into broad trends in the leading, "core-like" activities in the medium run of a few years or a decade. One way out of this bind was, in fact, already being worked through by Korzeniewicz and Martin in their rarely cited contribution to the original 1994 GCC edited volume. Their solution was to work in reverse - that is, they first empirically identified the "zones" of the world-system using income data and then parsed out national commodity production data by zone. In this way, Korzeniewicz and Martin were able to construct, for each commodity, indices of "core-ness" and "peripheral-ness" and identify changes in these indices over time. Yet, the kind of cross-nationally comparable commodity production data employed by Korzeniewicz and Martin are tremendously limited. To the extent that they can be collated, they are only available at a high level of aggregation (meaning they pertain to

\footnotetext{
${ }^{13}$ I thank an anonymous reviewer for helping me to better articulate my argument in relation to Arrighi and Drangel in this next section.
} 
relatively generic commodity categories), and the various classification systems developed by international and national data collection agencies lag - not surprisingly - quite far behind actual changes within the world-economy. It would appear that only Raphael Kaplinsky (2005), using commodity pricing data from the European Union, and Gary Hamilton, in conjunction with both Gary Gereffi (2009) as well as Richard Feenstra (2006) and using previously unavailable U.S. trade and customs data, have advanced a more nuanced and valid assessment of precise product category production and exchange relationships. However, all of these authors acknowledge the limitations of such data, mainly because they lack coverage of many important dimensions and geographical regions of the global division of labor.

The other way out of Arrighi and Drangel's tautological bind corresponds to the lacuna that I believe a "post paradox" GCC analysis is best suited to fill, and that is a more systematic effort to move "up and out" from analysis within chains to comparisons and linkages across chains. The major strengths of the GCC framework remain its capacity to illuminate firm and network-level dynamics with a granularity that cannot be achieved by cross-national quantitative data, as well as its abiding concern with governance and power effected through varying organizational and institutional frameworks. Upgrading, as a general organizing schema, has drawn attention toward increasingly detailed within-chain analysis; even when engaged in acrosschain analysis, it remains grounded in comparisons of relatively small segments of these chains

and narrowly delimited aspects of organization and governance therein. Thus, the revised path for which I am advocating does not constitute a new branch of GCC/GVC analysis so much as a shift in the schema used to organize and aggregate these insights from across chain-specific studies. Focusing more attention on whether, and how, changes within GCCs may or may not ultimately "add up" to country-level gains in wealth and development - and whether such gains persist over time - would position GCC/GVC analysis to make a far larger contribution to contemporary development and globalization studies. What is more, a broader review of the GCC/GVC literature, both from those working explicitly within the perspective as well as those skirting the edges of the field (exemplified by, but in no way limited to: Gibbon 2008; Gibbon and Ponte 2005; Kaplinsky 2005; O’Hearn 1994; Ponte and Ewert 2009; Schrank 2004) already reveals a good deal of work that undermines the upgrading discourse both empirically and theoretically. The challenge therefore has more to do with retraining our sights on the broader, cross-chain mechanisms and forces by which challenges to the global hierarchy of wealth may or may not have succeeded.

\section{CONCLUSION}

The fact that the GCC/GVC framework faces a "mid-life crisis" of sorts is in fact a testament to the vitality of the perspective; after all, a substantial research literature reflects the enduring intellectual appeal of this project. Thus, I would like to conclude by emphasizing what I believe to be the perspective's great strengths for those interested in charting ongoing changes in the global division of labor. In making the case for a "post-paradox" GCC analysis - one, that is, for which elucidating the mechanisms by which a durable trimodal distribution of global income has been reproduced during the twentieth century and into the twenty-first is the central explanandum - I have potentially risked reformulating, but nonetheless reproducing, the very critique of worldsystems analysis discussed above: functionalism. By emphasizing the stability of the global 
distribution of income and its connection to the claims of world-systems analysis, I by no means want to imply that this "fact" reflects some trans-historical, time-invariant structural property of the world-system. To the contrary, much of Wallerstein's writings for at least the past 20 years have focused on the anticipated breakdown and dissolution of the modern capitalist world-system and its particular global division of labor. And, as Arrighi's (1994, 2008) world-historical analysis even more powerfully demonstrates, the key to understanding capitalism as an historical social system is in accounting for its repeated reconstitution under new social, political, economic and ecological arrangements in successive cycles of world-scale accumulation.

The point here is not to judge the veracity or accuracy of Wallerstein's predictions in this respect, but merely to counter the misperception that world-systems analysis presumes a state of permanent stasis in the capitalist world-system or some such. From the start, GCC analysis has helped to clarify how this process of reorganization and reconstitution has proceeded, particularly in East Asia in the latter half of the twentieth century. A revived, "post-paradox" GCC analysis should have much more to contribute if, as many argue, even larger-scale shifts in the locus and organization of world-scale capital accumulation are currently underway. If this is the case - that is, if the capitalist world-economy is in the process of another such major reorganization - it may well be that the distinctly trimodal distribution of world income will be transformed as well. As such, my argument above should not be read as a justification for doing GCC analysis only to show how this system-level distribution of income has not changed. To the contrary, I take the GCC optic as highly attuned to the identification of whether, and how, such transformations occur, if trained on the correct phenomena. Such a focus can only be achieved, however, by casting aside the "upgrading" frame and the analytical contradictions it introduced, and committing to a renewed, "post-paradox" GCC analysis.

\section{ACKNOWLEDGEMENTS}

I am grateful to an anonymous reviewer for comments and suggestions on an earlier version; this review - the most extensive I have ever encountered - greatly improved the current version. Thanks as well to participants in the "Losing Our Chains: Rethinking the Commodity Chain Through Disarticulations" workshop in February, 2009 at Florida Atlantic University for comments on an earlier draft of this manuscript. This work was supported by the James Madison University Program of Grants for Faculty Educational Leaves.

\section{REFERENCES}

Arrighi, Giovanni. 1990. "The Developmentalist Illusion: A Reconceptualization of the Semiperiphery" Pp. 11-42 in Semiperipheral States in the World-Economy, edited by William Martin. New York: Greenwood Press. . 1994. The Long Twentieth Century: Money, Power and the Origins of our Times. New York: Verso. . 2008. Adam Smith in Beijing: Lineages of the Twenty-First Century. New York: Verso.

Arrighi, Giovanni and Jessica Drangel. 1986. "The Stratification of the World-Economy: An Exploration of the Semiperipheral Zone." Review 10(1): 9-74. 
Arrighi, Giovanni, Beverly J. Silver and Benjamin D. Brewer. 2003. "Industrial Convergence, Globalization and the Persistence of the North-South Divide." Studies in Comparative International Development 38(1): 3-31.

Babones, Salvatore. 2002. "Population and Sample Selection Effects in Measuring International Income Inequality." Journal of World-Systems Research VIII(I): 8-28. . 2005. "The Country-Level Income Structure of the World-Economy." Journal of World-Systems Research XI(I): 29-55.

Bair, Jennifer. 2005. "Global Capitalism and Commodity Chains: Looking Back, Going Forward." Competition \& Change 9(2): 153-180. . 2008. "Analysing Economic Organization: Embedded Networks and Global Chains Compared." Economy and Society 37(3): 339-364.

Bernstein, Henry and Liam Campling. 2006(a). "Commodity Studies and Commodity Fetishism I: 'Trading Down'?” Journal of Agrarian Change 6(2): 239-264. . 2006(b). "Commodity Studies and Commodity Fetishism II: 'Profits with Principles'?" Journal of Agrarian Change 6(3): 414-447.

Brady, David, Yunus Kaya and Jason Beckfield. 2007. "Reassessing the Effect of Economic Growth on Well-Being in Less-Developed Countries, 1980-2003." Studies in Comparative International Development 42(1): 1-45.

Collins, Jane. 2005. "New Directions in Commodity Chains Analysis of Global Development Processes." Research in Rural Sociology and Development 11: 3-17.

Dezzani, Raymond J. 2002. "Measuring Transition and Mobility in the Hierarchical WorldEconomy." Journal of Regional Science 42(3): 595-625.

Dowrick, Steve and Muhammad Akmal. 2005. "Contradictory Trends in Global Income Inequality: A Tale of Two Biases." Review of Income and Wealth 51(2): 201-29.

Dussel Peters, Enrique. 2008. "GCCs and Development: A Conceptual and Empirical Review." Competition \& Change 12(1): 11-27.

Feenstra, Robert C. and Gary G. Hamilton. 2006. Emergent Economies, Divergent Paths: Economic Organization and International Trade in South Korea and Taiwan. New York: Cambridge University Press.

Firebaugh, Glenn. 1999. "Empirics of World Income Inequality." American Journal of Sociology 104(6): 1597-1630. . 2000. "Observed Trends in Between-Nation Income Inequality and Two Conjectures." American Journal of Sociology 10(1): 215-221. . 2003. The New Geography of Global Income Inequality. Cambridge, MA: Harvard University Press.

Firebaugh, Glenn and Brian Goesling. 2004. "Accounting for the Recent Decline in Global Income Inequality." American Journal of Sociology 110(2): 283-312.

Gereffi, Gary. 1995. "Global Production Systems and Third World Development." Pp. 100-42 in Global Change, Regional Response: the New International Context of Development, edited by in B. Stallings. New York: Cambridge University Press.

Gereffi, Gary, John Humphrey and Timothy Sturgeon. 2005. "The Governance of Global Value Chains." Review of International Political Economy 12(1): 78-104.

Gereffi, Gary and Miguel Korzeniewicz (eds). 1994. Commodity Chains and Global Capitalism. Westport, CT: Praeger Publishers. 
Gereffi, Gary, Miguel Korzeniewicz and Roberto Patricio Korzeniewicz. 1994. "Introduction: Global commodity chains" Pp. 1-14 in Commodity Chains and Global Capitalism, edited by Gary Gereffi and Miguel Korzeniewicz. Westport, CT: Praeger Publishers.

Gibbon, Peter. 2008. "Governance, Entry Barriers, Upgrading: A Re-Interpretation of Some GVC Concepts from the Experience of African Clothing Exports." Competition \& Change 12(1): 29-48.

Gibbon, Peter, Jennifer Bair and Stefano Ponte. 2008. "Governing Global Value Chains: An Introduction." Economy and Society 37(3): 315-338.

Gibbon, Peter and Stefano Ponte. 2005. Trading Down: Africa, Value Chains, and the Global Economy. Philadelphia: Temple University Press.

Goesling, Brian and David P. Baker. 2008. "Three Faces of International Inequality." Research in Social Stratification and Mobility 26: 183-198.

Guthman, Julie. 2009. "Unveiling the Unveiling: Commodity Chains, Commodity Fetishism, and the 'Value' of Voluntary, Ethical Food Labels." Pp. 190-206 in Frontiers of Commodity Chain Research, edited by Jennifer Bair. Stanford, CA: Stanford University Press.

Hamilton, Gary G. and Gary Gereffi. 2009. "Global Commodity Chains, Market Makers, and the Rise of Demand-Responsive Economies." Pp. 136-61 in Frontiers of Commodity Chain Research, edited by Jennifer Bair. Stanford, CA: Stanford University Press.

Hopkins, Terrence K. and Immanuel Wallerstein. 1977. "Patterns of Development of the Modern World-System." Review 1(2): 111-145.

Kaplinsky, Raphael. 2005. Globalization, Poverty and Inequality: Between a Rock and a Hard Place. Cambridge, UK: Polity Press.

Korzeniewicz, Roberto Patricio and William Martin. 1994. "The Global Distribution of Commodity Chains.” Pp. 67-91 in Commodity Chains and Global Capitalism, edited by Gary Gereffi and Migual Korzeniewicz. Westport, CT: Praeger.

Korzeniewicz, Roberto Patricio and Timothy Patrick Moran. 1997. "World-Economic trends in the distribution of income, 1965-1992." American Journal of Sociology 102(4): 10001039 . . 2000. "Measuring World Income Inequalities." American Journal of Sociology 10(1): 209-214.

Korzeniewicz, Roberto Patricio, Angela Stach, Vrushali Patel and Timothy Patrick Moran. 2004. "Measuring National Income: A Critical Assessment." Comparative Studies in Society and History 46(3): 535-586.

Mann, Michael and Dylan Riley. 2007. "Explaining Macro-Regional Trends in Global Income Inequalities, 1950-2000." Socio-Economic Review 5(1): 81-115.

Milanovic, Branko. 2005. Worlds Apart: Measuring International and Global Inequality. Princeton, NJ: Princeton University Press.

Mills, Melinda. 2009. “Globalization and Inequality.” European Sociological Review 25(1): 1-8.

Moran, Timothy Patrick. 2003. "On the Theoretical and Methodological Context of CrossNational Inequality Data." International Sociology 18(2): 351-378.

Morris, Morris David. 1979. Measuring the Condition of the World's Poor. New York: Pergamon Press.

O'Hearn, Denis. 1994. "Innovation and the World-System Hierarchy: British Subjugation of the Irish Cotton Industry, 1780-1830.” American Journal of Sociology 100(3): 587-621. 
Palpacuer, Florence. 2008. "Bringing the Social Context Back In: Governance and Wealth Distribution in Global Commodity Chains." Economy and Society 37(3): 393-419.

Ponte, Stefano and Joachim Ewert. 2009. "Which Way is "Up" in Upgrading? Trajectories of Change in the Value Chain for South African Wine." World Development 37(10): 16371650 .

Quan, Katie. 2008. "Use of Global Value Chains by Labor Organizers." Competition \& Change 12(1): 89-104.

Raworth, Kate and Thalia Kidder. 2009. "Mimicking 'Lean' in Global Value Chains: It's the Workers Who Get Leaned On.” Pp. 165-189 in Frontiers of Commodity Chain Research, edited by Jennifer Bair. Stanford, CA: Stanford University Press.

Schrank, Andrew. 2004. "Ready-to-Wear Development? Foreign Investment, Technology Transfer, and Learning by Watching in the Apparel Trade." Social Forces 83(1): 123156.

Schwartz, Herman. 2007. "Dependency or Institutions? Economic Geography, Causal Mechanisms, and Logic in the Understanding of Development." Studies in Comparative International Development 42(1-2): 115-135.

Sen, Amartya. 1999. Development as Freedom. New York: Anchor.

Sturgeon, Timothy J.. 2009. "From Commodity Chains to Value Chains: Interdisciplinary Theory Building in an Era of Globalization." Pp. 110-135 in Frontiers of Commodity Chain Research, edited by Jennifer Bair. Stanford, CA: Stanford University Press.

Sutcliffe, Bob. 2004. "World Inequality and Globalization." Oxford Review of Economic Policy 20(1): 15-37.

Wade, Robert Hunter. 2004a. "On the Causes of Increasing World Poverty and Inequality, or Why the Matthew Effect Prevails." New Political Economy 9(2): 163-188. . 2004b. "Is Globalization Reducing Poverty and Inequality?" World Development 32(4): 567-589.

Wallerstein, Immanuel. 1974. The Modern World-System: Capitalist Agriculture and the Origins of the European World-Economy in the Sixteenth Century. New York: Academic Press. . 1991. "Development: Lodestar or Illusion?" Pp. 104-124 in Unthinking Social Science: The Limits of Nineteenth-Century Paradigms. Cambridge, UK: Polity Press. . 2004. World-Systems Analysis: An Introduction. Durham, NC: Duke University Press. . 2009. "Protection Networks and Commodity Chains in the Capitalist World-Economy." Pp. 83-90 in Frontiers of Commodity Chain Research, edited by Jennifer Bair. Stanford, CA: Stanford University Press. 